\title{
O TRABALHO DA ENFERMAGEM NA DETECÇÃO DE PROBLEMAS VISUAIS EM CRIAN- ÇAS/ADOLESCENTES
}

\author{
DETENTION OF VISUAL PROBLEMS IN SCHOOL CHILDREN AND ADOLESCENTS \\ EL TRABAJO DE ENFERMERÍA EN LA DETECCIÓN DE PROBLEMAS VISUALES EN NIÑOS/ADOLESCENTES
}

\author{
Carmen Luci R. LOPES ${ }^{1}$ \\ Maria Alves BARBOSA ${ }^{1}$ \\ Elisangela de S. MARQUES ${ }^{2}$ \\ Alexandra Isabel Amorim LINO2 \\ Nicolly Helen F. MORAIS ${ }^{2}$
}

\begin{abstract}
RESUMO - A detecção precoce de problemas visuais é uma medida de assistência primária importante. Este trabalho teve como principal objetivo, verificar a acuidade visual de crianças/adolescentes de uma escola conveniada de Goiânia-Goiás, utilizando o exame físico simplificado de saúde, através da Escala de Snellen. Das 414 crianças avaliadas, 46 (11\%) apresentaram deficiência visual e foram encaminhadas para consulta oftalmológica no Hospital das Clínicas da Universidade Federal de Goiás. Concluiu-se que o método de aferição da acuidade visual não está sendo amplamente adotado nas escolas, tal como indicado pelo Ministério da Educação através do programa de saúde ocular.
\end{abstract}

PALAVRAS CHAVES: Acuidade visual, escolar.

SUMMARY - The precocious detention of visual problems is a measure of important primary assistance. Thus being, this work had as main objective, to verify the visual level of children and adolescents in Goiânia (Goiás - Brazil) public school, being used the simplified physical examination of health through Snellen Table. Of the 414 evaluated children, $46(11 \%)$ had presented visual deficiency and had been directed for oftalmological consultation in the Hospital of the Clinics of the Federal University of Goiás.

WORDS KEYS: Visual acuity, pertaining to school

RESUMEN - La detección precoz de problemas visuales es una medida de asistencia primaria importante. Este trabajo tuvo como principal objetivo, verificar la agudeza visual de niños/adolescentes de una escuela conveniada de Goiania - Goiás, utilizando el examen físico simplificado de salud, a través de la Escala de Snellen. De los 414 niños analizados $46(11 \%)$ presentaron deficiencia visual y fueron dirigidos para consulta oftalmológica en el Hospital de Clínicas de la Universidad Federal de Goiás. Se concluyó que el método de verificación de la agudeza visual no está siendo ampliamente adoptado en las escuelas, como fue determinado por el Ministerio de Educación a través del programa de salud ocular.

PALABRA CLAVE: Agudeza visual, escolar.

\section{INTRODUÇÃO}

A visão é um dos mais importantes meios de comunicação, sendo que cerca de $80 \%$ das informações que recebemos são obtidas por seu intermédio. É, portanto, importante para o pleno desenvolvimento pessoal e relacionamento do indivíduo com o meio ambiente circundante (MINISTÉRIO DA SAÚDE, 1994).

Um fator a ser considerado, é o de que a visão é um aprendizado que evolui com o crescimento da criança. Ao nascimento o olho tem aproximadamente $3 / 4$ do tamanho do adulto. O crescimento pós-natal é máximo durante o primeiro ano, prossegue num ritmo rápido mais desacelerante até o terceiro ano, e continua num ritmo mais lento até a puberdade, e após esta, o crescimento adicional é insignificante. As várias partes do olho têm ritmos diferentes de crescimento. Em geral, as estruturas da parte anterior do olho crescem proporcionalmente menos do que as da porção posterior (NELSON, 1983).

Qualquer obstáculo à formação de imagens nítidas em cada olho, até que a acuidade visual esteja totalmente estabele-

1- Docentes da Faculdade de Enfermagem da Universidade Federal de Goiás

2- Acadêmicos da Faculdade de Enfermagem da Universidade Federal de Goiás 
cida, certamente levará a um mau desenvolvimento visual de caráter irreversível. Daí a importância em se eliminar precocemente qualquer determinante de má acuidade visual da criança, sendo recomendado levantamentos periódicos da população na faixa de 0 a 6 anos.(NETTO et. al, 1993.).

Entre 5 a $10 \%$ das crianças na faixa etária pré-escolar e 20 a $30 \%$ no grupo escolar, apresentam algum problema visual. A diminuição da visão acarreta o retardo no desenvolvimento e aprendizado da criança, com importante repercussão social. (ALVES et. al, 1991).

Segundo BRUNNER \& SUDDARTH (1998), o olho fornece estímulo visual para o córtex occipital. É importante testar a acuidade visual por ser ela a principal função ocular. Deve ser realizada primeiro, de modo que a visão seja avaliada antes que o olho seja realmente manipulado.

Os testes formais da acuidade visual formam a base de parte dos dados de cada paciente. A acuidade visual é testada com um gráfico ocular (tabela de Snellen ) colocado a $6 \mathrm{~m}$ do examinado. Solicita-se ao indivíduo examinado para cobrir um dos olhos com um pedaço de papel ou cartão mantendo os dois olhos abertos; em seguida, deve ler cada linha da tabela até que não possa mais distinguir os detalhes de um determinado tamanho da impressão. Se a pessoa usa óculos, sua acuidade deve ser avaliada com e sem lentes corretivas.

Se o examinado é analfabeto, recomenda-se o uso de tabelas "de Snellen" que mostrem a letra E em 4 diferentes posições. Isto também possibilita avaliar a visão de crianças com menos de 5 anos de idade.

Além deste fator que, em geral, é o que determina a escolha da técnica de exame a se utilizar, deve-se levar em conta o grau de inteligência, o tipo de comportamento e a capacidade de percepção, lembrando que a timidez e o medo na criança são obstáculos que devem ser superados quando se pretende uma medida fiel da acuidade visual (NETTO et. al, 1993).

Em cada 1.000 alunos do ensino fundamental, 100 são portadores de erros de refração, necessitando de correção (hipermetropia, astigmatismo e miopia). Aproximadamente $5 \%$ deles apresentam redução de acuidade visual, isto é, menos de $50 \%$ da visão normal. (BRASIL, 2000).

Um escolar nessas condições e sem os óculos só enxergará a lição se estiver muito próximo do quadro negro. Pesquisas indicam que a boa visão é essencial para melhorar o rendimento escolar (BRASIL, 2000).

Mais de $90 \%$ dos problemas oftalmológicos podem ser evitados ou minorados com educação preventiva e assistência curativa (BRASIL, 2000).

Do ponto de vista de saúde pública, é muito dispendioso e mesmo inexeqüível, a investigação de problemas oculares em crianças, por oftalmologistas, em exame de massa. Conforme afirma WICK; RICKER (1976), o especialista deve trabalhar num grau mais alto de competência, avaliando e corrigindo problemas e não pesquisando os normais.

Dessa maneira, a solução é de aplicação de triagem oftalmológica por pessoal não médico, treinados e supervisionados, em populações aglutinadas em escolas, ou clientela que procura serviços pediátricos do Estado, dentro do grupo etário onde os problemas visuais se apresentam como prioridade (BRIK, 1971).

È importante considerar as observações de professores do ensino fundamental quanto aos sinais apresentados por seus alunos na sala de aula referentes 'a visão. Estas observações e a aplicação do teste de acuidade visual são formas valiosas pare a detecção de problemas visuais.

Com o intuito de contribuir com a redução dos problemas visuais em escolares, este trabalho teve como objetivos, aplicar o teste de acuidade visual em crianças/adolescentes de uma escola municipal conveniada e encaminhar ao oftalmologista aquelas que apresentaram deficiência visual após avaliação através da Escala de Snellen.

\section{METODOLOGIA}


Trabalho de campo, cuja população constitui-se de 414 escolares na faixa etária de 5 a 14 anos do pré-escolar à $4^{\circ}$ série de uma escola conveniada de Goiânia-Goiás no período de agosto a dezembro de 2001.

Os testes de acuidade visual através da aplicação da Tabela de Snellen, foram realizados por acadêmicos de Enfermagem da Universidade Federal de Goiás, previamente treinados. Após a realização dos testes, as crianças que apresentaram resultado da acuidade visual inferior a $80 \%$, tiveram consultas agendadas com oftalmologistas do Hospital das Clínicas da Univer- sidade Federal de Goiás através da Secretaria Municipal de Saúde. Os pais foram informados sobre a data das mesmas e concordaram em acompanhar as crianças.

\section{RESULTADOS E DISCUSSÃO}

As características dos 414 escolares da Escola Municipal da Escola Conveniada de Goiânia-Goiás estão apresentadas na tabela I. Verificou-se que a maioria dos participantes era do sexo masculino (54\%). A média da idade encontrada foi de 9 anos. Em relação à série cursada, a maioria $(21 \%)$ estava matriculada na $1^{a}$ série.

Tabela I-Distribuição dos escolares em relação ao sexo, idade, turno e série- Escola Municipal Conveniada Goiânia-Goiás. 2002.

\begin{tabular}{lcc}
\hline Características & $\mathrm{F}$ & $\%$ \\
\hline Sexo & 231 & \\
Masculino & 183 & 56 \\
Feminino & & 44 \\
Idade & 194 & 46,85 \\
$05-08$ & 189 & 45,65 \\
$09-12$ & 31 & 7,5 \\
$12-15$ & & \\
Série & 57 & 13,76 \\
Pré-escolar & 89 & 21,49 \\
$1^{\text {a }}$ & 80 & 19,32 \\
$2^{\text {a }}$ & 76 & 18,35 \\
$3^{\text {a }}$ & 72 & 17,39 \\
$4^{\text {a }}$ & 40 & 9,6 \\
Aceleração & & \\
Turno & & 49 \\
Matutino & 202 & 52 \\
Vespertino & 212 & \\
\hline
\end{tabular}

A tabela II mostra o resultado do teste realizado, sendo que, dos 414 alunos examinados $46(11 \%)$ apresentaram acuidade inferior a $80 \%$. A porcentagem encontrada é pouco superior ao valor de $10 \%$ considerado normal pelo Ministério da Saúde.

Em estudos realizados no Brasil, observou-se percentuais variados como: $6,3 \%$ (CANO et. al, 1995); 14\% (ALVES et. al, 1991); 31,1\% (MOURA et. al, 2000).

Tabela II - Resultado do teste de acuidade visual dos escolares da Escola Municipal Conveniada Goiânia -Go. 2002. 


\begin{tabular}{lcc}
\hline Acuidade visual & $\mathrm{F}$ & $\%$ \\
\hline normal & 368 & 89 \\
deficiente & 46 & 11 \\
total & 414 & 100 \\
\hline
\end{tabular}

Na tabela III, observa-se a deficiência da acuidade visual em relação à idade. NETTO et. al, observaram ainda que há aumento do percentual de deficiência da acuidade com o aumento da idade. Neste estudo, constatou-se que o maior acometimento encontrado foi na faixa etária de 6 a 8 anos equivalendo a $52,2 \%$.

Tabela III - Resultado do teste de acuidade visual dos escolares da Escola Municipal Conveniada Goiânia -Go de acordo com a idade.

\begin{tabular}{lcc}
\hline Faixa etária & $\mathrm{F}$ & $\%$ \\
\hline $6-8$ & 24 & 52,2 \\
$9-12$ & 22 & 47,8 \\
total & 46 & 100 \\
\hline
\end{tabular}

\section{CONSIDERAÇÕES FINAIS}

Apesar do método de aferição da acuidade visual por meio da aplicação de testes que utilizam sinais, ganchos, letras ou figuras (optópitos).ser de simples execução, de baixo custo e de oferecer um certo grau de segurança no resultado do exame, observou-se neste trabalho, que, o mesmo não está sendo amplamente adotado nas escolas, como indicado pelo Ministério da Educação através do programa de saúde ocular.

Considerando portanto, a influência da identificação precoce dos problemas visuais no desenvolvimento intelectual e psicossocial da criança e a importância da assistência preventiva, sugerimos que seja colocado em prática, a realização do teste de acuidade visual com todos os escolares assim que matriculados e que sejam encaminhados para consulta oftalmológica todos os que apresentarem deficiência visual.

\section{REFERÊNCIAS BIBLIOGRÁFICAS}

ALVES, João Guilherme Bezerra; CAVALCANTI, Helman Dantas de Olinda - Acuidade visual em escolares atendidos no ambulatório do Instituto Materno Infantil de Pernambuco. Revista do IMIP. v. 5, 1991.

BRASIL - campanha nacional olho no olho2000.

BRASIL, MINISTÉRIO DA SAÚDE - Secretaria da Assistência à saúde. Departamento de Assistência e Promoção à Saúde. Coordenação de Doenças Crônicodegenerativas. Informações básicas para a promoção da saúde ocular, 2. ${ }^{a}$ ed. Brasília, 1994.

BRIK, M. - Profilaxia da Ambliopia .Contribuição para o estudo do problema. Arq. Bras. Oftal., v.34, 1971.

BRUNNER \& SUDDARTH. Tratado de Enfermagem Médico-cirúrgica. v. 2. Guanabara Koogan, 1998.

CANO, M.A.T; SILVA, G.B. - Detecção de problemas visuais e auditivos de escolares em Ribeirão Preto: Estudo comparativo por nível sócio econômico. Revista Latino - Americana de Enfermagem. v. .2 , p. 57-68,1994. 
MOURA, Maria Aparecida Vasconcelos; BRAGA, Maria Ferreira da Costa - O exame da acuidade visual como medida preventiva. Escola Anna Nery, Revista de Enfermagem. Rio de Janeiro v. 4, p. $37-45,2000$.

NELSON, Waldo E.- Tratado de Pediatria. $11^{a}$ ed. v. II. Rio de Janeiro, 1983.

NETTO, Augusto Adam.; WERNER Alexandre; ROSA, Evandro Luis - Deficiência da acuidade visual em pré-escolares. Arquivos Catarinenses de Medicina. v. 22, 1993.

TEMPORINI, E. R. - Validade da aferição da acuidade visual realizada pelo professor em escolares de $1 .^{a}$ a $4 .^{a}$ série de primeiro grau de uma escola pública do município de São Paulo, Brasil. Rev. Saúde Pública, S. Paulo, p. 22937,1971 . 